\title{
O terceiro setor na educação de adultos: tensões e ambivalências
}

\author{
Paula Guimarães ${ }^{i}$ \\ Universidade de Lisboa, Portugal
}

\begin{abstract}
Resumo
O terceiro setor tem ocupado um lugar importante na promoção da educação de adultos e na mudança social em comunidades locais que se encontram cada vez mais excluídas de processos hegemónicos de desenvolvimento económico. Todavia, muitas organizações têm adotado estratégias de mediação entre o Estado e as comunidades locais, no âmbito de parcerias, e passaram a partilhar com as empresas algumas características que põem em causa a sua autonomia e a sua capacidade de desenvolver projetos educativos de carácter crítico e emancipatório. Este artigo procura debruçarse sobre as transformações ocorridas no terceiro setor com intervenção na educação de adultos, a partir de dados recolhidos no quadro de um projeto de investigação que privilegiou o estudo de caso da política pública de educação e formação de adultos adotada após 1999 e implementada por uma associação de desenvolvimento local.
\end{abstract}

Palavras-chave

Educação de adultos; Terceiro setor; Política pública

\section{Sobre o Estado, a sociedade civil e o terceiro setor}

O Estado e a sociedade civil são habitualmente tidos como dois conjuntos de atores e instituições que se opõem. De acordo com Santos (1990), o Estado caracteriza-se por assentar numa organização formal, sendo "detentor de uma unidade interna e de soberania, apoiado num sistema 
jurídico unificado e centralizado, convertido numa linguagem universal através da qual comunica com a sociedade" (p. 20). Pelo seu lado, a sociedade civil abarca "o domínio da vida económica, das relações sociais espontâneas orientadas pelos interesses privados e particularísticos" (Santos, 1990, p. 20). O mesmo autor argumenta que, definidos a partir do princípio da separação, o Estado traduz o formalismo, o coletivismo, a estruturação e a regulação, entre outras características, enquanto a sociedade civil é marcada, por exemplo, pelo informalismo, civilismo, individualismo e privatismo. Neste sentido, o Estado condiciona a liberdade individual e, em simultâneo, o seu exercício, enquanto a sociedade civil se apresenta como o espaço de prática da liberdade, em domínios tão diversos como a economia, a participação cívica e a cultura, entre outros (Santos, 1990, pp. 15-19).

Se, teoricamente, esta dualidade permitiu a compreensão das relações entre Estado e sociedade civil nos países capitalistas até meados do século $\mathrm{XX}$, nomeadamente no contexto da consolidação do Estado-providência, mais recentemente, no quadro do capitalismo desorganizado e da crise da referida forma de Estado, ressaltam as tensões (Griffin, 1999a, 1999b). Nesta linha de ideias, até finais da década de 1960, os países capitalistas assistiram à expansão do Estado (e à retração da sociedade civil), e, desde então, registaram-se mudanças na regulação económica e social estatal, nos padrões da democracia representativa, na estrutura e na intervenção dos partidos políticos e dos sindicatos, entre outras, que atribuem primazia à sociedade civil. Passou a verificar-se então uma "aproximação e interpenetração do Estado e da sociedade civil", levando a que cada termo deste binómio se esteja "progressivamente a transformar no duplo do outro" (Santos, 1990, p. 23).

Adicionalmente, como refere Monteiro, a expressão sociedade civil tem sido utilizada como equivalente de terceiro setor. Segundo este autor, o terceiro setor agrupa

(...) organizações civis, resultantes do esforço e vontade de associação voluntária de cidadãos, distintas tanto das instituições coercivas do Estado (...), como das instituições lucrativas do mercado, mobilizando os cidadãos para causas públicas e promovendo pela sua acção a estabilidade e efectividade das democracias (Monteiro, 2004, p. 150). 
Em decorrência, o terceiro setor integra um conjunto alargado e heterogéneo de organizações que se orientam por finalidades diversificadas de natureza social, cívica, política, cultural, económica, etc. Apesar de diversas, estas entidades podem apresentar-se como espaços de autogovernação, no âmbito da limitação dos poderes do Estado ou até da concretização de estratégias de oposição a este último. Estas entidades podem estabelecer parcerias com o Estado e, embora não possuam fins lucrativos, podem igualmente receber apoios de empresas, por exemplo, através do mecenato. Por esta razão, situam-se, mesmo que teoricamente, em alternativa ao Estado e ao mercado. De resto, o hibridismo e a complexidade do terceiro setor faz com que seja apelidado de "público não estatal" ou "privado não lucrativo de interesse público" (Lima \& Afonso, 2006).

Se se atentar nos desenvolvimentos históricos relativos à sociedade civil, designadamente na Europa do Centro e do Norte, é de destacar que o associativismo emergiu ainda no século XIX como alternativa ao capitalismo. Possui assim "raízes ideológicas heterogéneas que iam do socialismo ao cristianismo social e ao liberalismo" (Santos, 1998, p. 6). Estas associações preferiam novas formas de organização da produção e do consumo que punham em causa os princípios da economia política de então. Procurava-se dessa forma minimizar os custos que a Revolução Industrial acarretara. Neste quadro, a autonomia associativa começou por ser essencial no esbatimento das desigualdades causadas pela organização capitalista e pela intervenção do Estado e as associações assumiram-se como instrumentos contra o Estado, de resistência a um sistema de produção promotor da alienação (Santos, 1998). Na segunda metade do século passado, o Estado-providência e as políticas redistributivas implementadas em diversos domínios sociais implicaram a metamorfose do associativismo e vieram retirar alguma relevância à intervenção da sociedade civil. Contudo, em particular nas últimas décadas, registou-se a reemergência de muitas associações, designadamente do terceiro setor, associada à crise do Estado social e à adoção de orientações neoliberais. Esta circunstância ocorreu num momento de diminuição de políticas progressistas em que os direitos humanos da terceira geração, os direitos económicos e sociais, conquistados depois de 1945, começaram a ser postos em causa (Santos, 1998, p. 8). Consequentemente, a retração estatal permitiu a criação de espaços de 
intervenção que o terceiro setor tem ocupado na satisfação de necessidades sociais e educativas das populações locais (Turner, 2001, p. 199), assumindo, por essa via, um papel de parceiro (e já não de opositor do Estado) na implementação de políticas públicas.

\section{O terceiro setor e a educação de adultos em Portugal}

A ligação entre o terceiro setor e a sociedade civil levanta diversas questões no que remete para a articulação com o próprio Estado. Como afirma Santos (1994), a sociedade civil em Portugal revela marcas muito específicas, podendo ser considerada simultaneamente fraca, se se pensar nas formas de organização dominantes nos países centrais, no que respeita à participação e à cidadania, e forte, em termos de estruturas familiares, redes de solidariedade e de vizinhança. Segundo este autor, tem sido esta força que, nos últimos tempos, tem permitido compensar as debilidades do (semi) Estado-providência português em construção após o 25 de abril de 1974, mas, desde então, em crise. De resto, esta tem sido uma das especificidades de Portugal, um paradoxo no qual radica a simultaneidade da consolidação e da retração do Estado social nas últimas quatro décadas (Lima, 1995).

O terceiro setor destacou-se assim no contexto da crise do Estado, de fortes críticas à intervenção pública considerada burocrática e pouco flexível, originadora de desigualdades sociais complexas e cada vez mais acentuadas. Para autores como Melo (2007), mais otimistas sobre as suas potencialidades, o terceiro setor surgiu como sendo mais eficiente e eficaz no cumprimento das funções sociais que anteriormente tinham sido realizadas ou tentadas pelo Estado. Neste cenário, verificaram-se novas formas de organização social e política mais solidárias e participativas, de promoção da autonomia e da emancipação. Para outros autores, como Lima e Afonso (2006), contudo, o terceiro setor passou a adotar formas de trabalho e modos de regulação mais próximos do próprio Estado e das empresas, uma vez que passou a depender cada vez mais das políticas públicas e dos programas de financiamento estatais e supranacionais para a sua existência. Questiona-se assim a sua autonomia, assim como a sua capacidade de intervenção transformadora na sociedade civil (Monteiro, 2004). Devido a estas razões, esta ação tem envolvido ambivalências que resultaram da ligação próxima que o terceiro setor possui relativamente ao Estado e ao mercado, sobretudo 
no que concerne às finalidades das iniciativas levadas a cabo, bem como aos modos de funcionamento interno das entidades, devido às regras formais impostas pele gestão dos projetos financiados.

Hoje, o terceiro setor encontra-se sob forte pressão. A profissionalização dos seus recursos humanos surge como uma imposição na procura de apoios financeiros e como uma estratégia de sobrevivência institucional. Por outro lado, a maximização dos meios obtidos exige a adoção de orientações gerencialistas. Verifica-se assim, em muitos casos, um afastamento relativamente a finalidades mais autonómicas e a estratégias de intervenção local emancipatórias características de certas organizações nãogovernamentais (Lima, Guimarães, \& Oliveira, 2007).

Assim, sendo, em Portugal, bem como noutros países europeus, o terceiro setor acumula uma significativa experiência no campo da educação de adultos (Ruas, 1978; Norbeck, 1983; Comissão de Reforma do Sistema Educativo, 1988), tanto nas modalidades formal, como não formal e informal (Canário, 2007). Como argumenta Canário, o associativismo de raiz popular forneceu o esteio para o desenvolvimento de modalidades tão diversas como o mutualismo, o cooperativismo, a intervenção cultural e de recreio no período anterior ao Estado Novo. Mais tarde, de meados da década de 1920 até 1974, apesar de profundamente condicionado, as associações representaram "uma rede de trincheiras que serviu de retaguarda à ação política e como uma escola de militantes sociais e políticos" (Canário, 2009, p. 133). Este foi um período caracterizado por uma forte coerção exercida pelo poder político autoritário, em que estas entidades procuraram criar formas imaginativas de resistência política e social.

Logo após o 25 de abril, as associações populares surgiram como alavancas da iniciativa popular, da rutura social e política com vista à criação de um poder local democrático forte. Foi neste contexto que receberam enquadramento legislativo (através do Decreto-Lei n. ${ }^{\circ} 384$, de 20 de maio de 1976). Esta situação permitiu-lhes promover atividades de educação emancipatória, apoiar o movimento social pujante de então, na procura de uma sociedade mais justa e democrática. Neste quadro, coube ao Estado a disponibilização de recursos a estas entidades e a promoção social, cultural e educativa dos seus associados. Pelo seu lado, estas associações levaram a cabo ações que seriam certificadas formalmente pelo Ministério da Educação 
(Melo \& Benavente, 1978). Verificou-se assim o fomento de projetos de "educação crítica e transformadora, locais de produção multicultural e educativa orientada para a cidadania democrática, a mudança social e a justiça" (Lima, 2012, pp. 105-106), numa articulação profícua entre o Estado e a sociedade civil.

Apesar do interesse desta ligação, ela acabou por ser progressivamente abandonada a partir de 1976, embora retomada em 1979, no âmbito do Plano Nacional de Alfabetização e Educação de Base de Adultos. Verificou-se de novo o destaque no papel das associações na educação de adultos. Todavia, as dificuldades na implementação desta proposta, de resto abandonada em meados da década de 1980, afastaram progressivamente as entidades da sociedade civil da política pública preconizada então (Silva, 1990).

Depois da adesão de Portugal à Comunidade Económica Europeia, em 1986, mesmo à margem da política pública de educação de adultos, muitas organizações do terceiro setor reafirmaram o seu dinamismo ao candidatarem-se a programas apoiados pelo Fundo Social Europeu. Esta circunstância permitiu o desenvolvimento de projetos muito diversos, de formação profissional, de desenvolvimento local (no âmbito do LEADER, por exemplo), de luta contra a pobreza (como no caso do programa EQUAL), de apoio e defesa das mulheres (designadamente no âmbito do NOW), etc. Estas iniciativas integraram, entre outras, atividades de educação não formal e espelharam a riqueza, a criatividade e o potencial democrático e autonómico da intervenção local (Monteiro, 2004; Fragoso \& Guimarães, 2010).

Em suma, globalmente, a história da educação de adultos em Portugal, desde o 25 de abril de 1974, permite identificar variações nas relações entre o Estado e as organizações da sociedade civil. Nesta linha de ideias, Lima (2012) identifica três tipos de relações. O primeiro inclui as organizações que promovem projetos de "educação crítica e transformadora, locais de produção multicultural e educativa orientados para a cidadania democrática, a mudança social e a justiça". A autonomia destas organizações desenvolve-se no sentido de procurar novas formas democráticas de autogoverno, a participação ativa em processos políticos, a democratização da democracia formal, do Estado e das instituições políticas. Estas entidades surgem como espaços de mobilização social e de politização das práticas sociais e educativas que 
contribuem para a reinvenção democrática do Estado e para a autorregulação da sociedade civil (Lima, 2012, pp. 105-106). Neste quadro, estas organizações adotam políticas globais e integradas que evocam uma solidariedade orientada para reestabelecer a dimensão social e a responsabilidade cívica da vida em sociedade (Laville, Evers, Poujol, \& Vaillancourt, 1997, p. 354). Por estes motivos, as políticas públicas de educação de adultos que decorrem deste tipo de relações orientam-se para a promoção da cidadania democrática, bem como para a participação na transformação social. A mobilização social e política consiste num processo de educação e aprendizagem social essenciais, produtos da ação política e da conscientização (Guimarães, 2011; Lima, 2012).

O segundo tipo contempla as organizações que se apresentam como "extensões burocráticas, serviços locais do Estado e da administração pública ou ainda como parceiros da provisão social e educativa pública". São entidades sob forte regulação estatal e dependem das autoridades públicas, estando orientadas para a gestão dos problemas sociais e da exclusão social, sobretudo através de processos de adaptação funcional de acordo com objetivos das políticas públicas em vigor. Como afirma Lima, estas organizações intervêm num contexto de devolução estatal. Neste caso, o terceiro setor assume-se como parceiro do Estado. Obtendo financiamento estatal, organiza-se e intervém adotando formas e procedimentos isomórficos, mais próximos do modo de funcionamento de organizações públicas. Por esta razão, "subordina-se a agendas públicas, especializa-se na gestão da crise e procura promover o consenso" (Lima, 2012, pp. 106-107). O Estado vê assim o seu papel de prestador de serviços assegurado, com o objetivo de concretização da igualdade de oportunidades e de justiça social. Regista-se por esta via uma concertação interinstitucional entre serviços estatais e o terceiro setor, no qual este último se apresenta como um importante auxílio do Estado social. As iniciativas levadas a cabo dirigem-se preferencialmente a sujeitos desfavorecidos do ponto de vista social e económico (Laville et al., 1997, pp. 351-352). Aqui, a educação de adultos tende a preencher objetivos de controlo e regulação social, bem como de modernização educativa. A educação de segunda oportunidade e a formação profissional são privilegiadas (Guimarães, 2011; Lima, 2012). 
Um terceiro tipo de organizações contempla aquelas que se apresentam como entidades "de cultura corporativa e de ethos empresarial, orientadas para o mercado da aprendizagem e seus respectivos clientes" (Lima, 2012, pp. 107-108). São organizações que se situam entre a sociedade civil e o mercado, numa alternativa ao Estado-providência burocrático. Num esforço de reduzir custos e de personalizar serviços, o Estado aposta nestas entidades, considerando-as mais racionais, eficientes e eficazes na prestação pública. Promovem atividades nas quais se concede maior autonomia aos indivíduos e maior capacidade de escolha, podendo as iniciativas ser custeadas quer pelos sujeitos, quer pelo Estado. Por este motivo, os indivíduos são vistos como consumidores. A competição entre estas entidades é induzida pelo Estado, através da introdução de regras de mercado, na procura da excelência (Laville et al., 1997, pp. 345-349). A aprendizagem, vista como um estilo de vida, apresenta-se como um elemento central na construção de percursos de formação individuais racionais, com impacto em termos competitivos e de produtividade. Espera-se que os adultos envolvidos estejam particularmente interessados em aprender e em competir pelo progresso. A aprendizagem e a educação ao longo da vida tendem a estar subordinadas a modelos de formação profissional e a conceitos como qualificação, competências e capacidades com valor económico (Guimarães, 2011; Lima, 2012).

\section{Política pública de educação e formação de adultos e o terceiro sector}

Em Portugal, nos finais da década de 1990, o terceiro setor foi remobilizado no quadro da política pública. De facto, no contexto da estratégia para o desenvolvimento da educação de adultos, apostou-se na dinamização da sociedade civil. Neste sentido, afirmou-se que a educação de adultos deveria promover um sistema educativo e de intervenção cívica apoiado em parcerias. Estas envolveriam entidades muito distintas (públicas, privadas e não governamentais). Para isso, apontou-se para a articulação entre duas lógicas distintas, a lógica de serviço público e a lógica de programa. Através da lógica de serviço público, a intervenção do Estado seria essencial na conceção, no desenvolvimento e na avaliação de ofertas que se centrariam sobre a educação de base e forneceriam uma certificação académica, 
assegurando a existência de uma rede pública de ofertas educativas. A lógica de programa, baseada na valorização de projetos, de iniciativas e experiências pedagógicas, procuraria a "disponibilização, através de concurso, de apoios financeiros e outros para as iniciativas da sociedade civil de melhor qualidade e maior impacto na construção do sistema de educação e formação de adultos" (Melo, Queirós, Silva, Rothes, \& Ribeiro, 1998, p. 15).

Nesta linha de ideias, mais uma vez, o terceiro setor surgiu como um espaço de autonomia e construção da cidadania participativa. Mas, a articulação entre as lógicas indicadas revelou-se particularmente ambivalente e denotou tensões no papel de mediação desempenhado por muitas entidades. Numa primeira linha, a política de educação e formação de adultos implementada na última década recorreu a princípios sustentadores do Estado-providência, designadamente no que respeitou ao envolvimento do Estado em ofertas de educação de base formal e não formal, ao acesso e ao alargamento da participação dos parceiros sociais na definição e adoção de políticas económicas, sociais e educativas, integradas, por exemplo, no Plano Nacional de Emprego, no Plano Nacional de Desenvolvimento Económico e Social de Médio Prazo e nos Acordos de Concertação Estratégica. Numa segunda linha, esta opção envolveu a inscrição das parcerias num Estado social em retração, evidente nos acordos estabelecidos para a promoção de ofertas de educação de base como o Reconhecimento, Validação e Certificação de Competências e os Cursos de Educação e Formação de Adultos (Guimarães, 2011).

Assim, no quadro da política pública de educação e formação de adultos, as entidades do terceiro setor surgiram no cruzamento de diferentes tipos de relações estabelecidas com o Estado. De um lado, assumiram-se discursivamente como entidades promotoras de ações de educação crítica, cidadania democrática, de transformação social e participação, enquanto evidenciavam características de organizações do segundo setor no âmbito do desenvolvimento de atividades de educação de base. De outro lado, revelavam padrões de intervenção mais próximos de "entidades empresariais" (Lima, 2012, pp. 107-108), no que respeitava aos modos de funcionamento interno e de gestão do sistema efetuados pelos departamentos estatais responsáveis. Esta situação originou ambiguidades no trabalho realizado pelo terceiro setor no campo da educação de adultos que decorreu 
de dois fatores. Num primeiro momento, acarretou uma 'crise de valores' da missão e o compromisso destas entidades com as comunidades locais, dado que, ao dinamizarem certas ofertas, substituíam-se ao Estado e desviavamse das finalidades para que tinham sido criadas. Num segundo momento, implicou uma 'crise de funcionamento': a atividade do terceiro setor passou a ser profundamente regulada e formalizada e foram abandonadas práticas organizacionais informalizadas, mais tradicionais nestas entidades. Esta regulação decorreu, entre outros, dos sucessivos momentos de avaliação e de prestação de contas que passaram a marcar o dia a dia destas organizações (Laville et al., 1997, pp. 324-325). Adicionalmente, o terceiro setor revelou-se como um espaço de promoção de atividades de educação de adultos "socialmente induzidas", realizadas "com base em estruturas organizativas complexas e por técnicos ou profissionais qualificados, por referência e com recurso a programas estatais cuja finalidade consistia em procurar soluções para problemas locais, percepcionados ou identificados por organismos da administração central" (Guimarães, Silva, \& Sancho, 2006, p. 68). Desde então, passou a ser particularmente frequente a ocorrência de iniciativas enquadradas em projetos de caráter nacional. Sendo disseminadas através de programas de financiamento, as ações implementadas envolveram uma elevada complexidade procedimental, significativos recursos económicos e um corpo de técnicos qualificados que candidatavam projetos, vigiavam a implementação das atividades e procediam à avaliação dos resultados obtidos, garantindo por essa via a sobrevivência institucional dessas organizações. Estas mudanças tiveram reflexos sobre a estrutura das atividades desenvolvidas (Laville et al., 1997, pp. 326-331), agora redefinida em função das prerrogativas estatais. As transformações registadas acentuaram igualmente modos de trabalho mais próximos das entidades com fins lucrativos, na procura da eficácia e da eficiência, de uma gestão racional (mesmo que não lucrativa) dos recursos conseguidos e um aumento da produtividade no seio de equipas que deviam ser qualificadas, empreendedoras, flexíveis, responsáveis e inovadoras (mesmo que raramente bem pagas).

\section{Percurso metodológico}

Este artigo baseia-se numa investigação qualitativa inscrita no paradigma interpretativo (Lessard-Hébert, Goyette, \& Boutin, 2005), assente 
num estudo de caso, entendido como uma pesquisa detalhada de um objeto específico (Bogdan \& Biklen, 1982; Yin, 1994). O estudo incidiu sobre uma política pública - a educação e formação de adultos (Grupo de Missão para o Desenvolvimento da Educação e Formação de Adultos, 2001) - concretizada no terreno por uma associação de desenvolvimento local. No âmbito desta investigação, este texto procurou encontrar respostas para a seguinte questão: como é que os agentes de uma associação de desenvolvimento local (uma organização do terceiro setor) interpretam o papel de mediação levado a cabo por essa associação, aquando da implementação de ofertas públicas de educação e formação de adultos (no que remete especificamente para as relações estabelecidas com o Estado)? A hipótese de trabalho destacou as parcerias estabelecidas entre essa associação e o Estado, estando essas assentes numa conceção complexa de organização da sociedade civil como "extensão de serviços de educação de adultos públicos" (Lima, 2012) dotada, todavia, de um discurso de educação crítica e transformadora, bem como "entidade do terceiro setor profissionalizada de prestação de serviços de educação, formação e aprendizagem ao longo da vida" (Laville et al., 1997).

Os dados mobilizados na redação deste artigo resultaram de seis entrevistas a atores dessa associação, nomeadamente dirigentes (2) e técnicos (4). A preferência por entrevistas semiestruturadas favoreceu o confronto dos sentidos atribuídos pelos entrevistados a certos acontecimentos, práticas, contextos, etc. (Lessard-Hébert, Goyette, \& Boutin, 2005) e permitiu privilegiar os discursos e as representações dos indivíduos que participaram no desenvolvimento de uma oferta pública específica de educação de adultos, designadamente Cursos de Educação e Formação de Adultos, entre 2001 e 2005. Recorreu-se igualmente à análise documental, designadamente de textos escritos sobre a atividade da associação (por exemplo, os estatutos da associação, os relatórios de execução de projetos e os levantamentos de necessidades de educação e formação).

Depois de obtidas, estas informações foram sujeitas à análise de conteúdo categorial (Bardin, 1977), tendo estas categorias sido definidas a posteriori, após leitura das entrevistas transcritas. Foram utilizados neste texto dados associados à categoria intervenção da associação na educação de adultos, no quadro da política pública, nomeadamente no que remeteu para as subcategorias finalidades da associação, projeto educativo e papel dos agentes da educação e formação de adultos. 


\section{Uma associação de desenvolvimento local entre a pedra e a corrente}

A associação de desenvolvimento local ${ }^{1}$ tinha por objetivo principal "promover o desenvolvimento rural integrado" (Art. ${ }^{\circ} 2 .^{\circ}$ dos Estatutos), de acordo com um entendimento abrangente desta ideia. Assim, segundo um dos entrevistados,

[Quanto aos objetivos perseguidos pela associação] Posso resumi-los a um mais alargado que é o desenvolvimento rural integrado, ou seja a melhoria das condições de vida das populações do meio rural, essencialmente. Desde as condições de habitação das populações, dos núcleos rurais mais concentrados na montanha, onde há mais dificuldades; as condições económicas, como a possibilidade de apoiarmos pequenas e médias indústrias; o artesanato; os produtos locais; o turismo rural... (...) Desde logo, parte da promoção [de produtos locais] também; damos apoio para que a nossa região, o nosso produto, o nosso património seja divulgado e promovido, não só ao nível interno, mas ao nível externo, porque também temos participado em várias feiras temáticas no estrangeiro $[\mathrm{E}(\mathrm{T}) 1]$.

A associação foi fundada em 1991, partindo da iniciativa de cinco pessoas (que exerciam funções em entidades públicas locais), na sequência da implementação de um Plano de Desenvolvimento Agrário Regional (PDAR), neste caso específico para o Alto Cávado. Este documento preconizou a constituição ao nível regional de uma entidade privada de desenvolvimento rural. A partir de então e seguindo uma tendência evidente para o caso de outras entidades do género (Monteiro, 2004), a associação efetuou uma candidatura ao Programa de Iniciativa Comunitária LEADER I. A sua aprovação e consequente implementação permitiu até 2007 a realização de 232 projetos em áreas tão diversificadas como o apoio técnico, a formação profissional e a educação de adultos, o turismo em meio rural, o artesanato $\mathrm{e}$ a criação de pequenas e médias empresas, a promoção dos produtos agrícolas locais e a proteção do ambiente (Lima, Guimarães, \& Oliveira, 2007). Apesar de se apresentar como uma entidade da sociedade civil, as sucessivas candidaturas evidenciavam o papel de mediação de uma "organização enquanto extensão burocrática de serviços sociais orientada para a gestão de problemas sociais específicos" (Lima, 2012), afastando possibilidades de realização de ações de educação crítica e transformadora, de promoção da cidadania democrática e da participação. 
Não sendo a realização de iniciativas de educação de adultos a principal finalidade da associação, as ações dirigidas aos adultos aumentaram em número desde meados da década de 1990, em resposta às oportunidades concedidas pelos programas existentes e às características da comunidade local. Devido a este facto, esta associação nunca possuiu um projeto educativo coerente e arreigado nas finalidades que melhor a caracterizavam, revelando uma orientação auto-centrada em objetivos inicialmente estabelecidos, na consolidação, no alargamento e no enriquecimento de uma estrutura organizacional e de gestão característica da intervenção de outras associações de desenvolvimento local (Monteiro, 2004, pp. 235-236). Como afirmou um dos inquiridos,

Para mim, aquilo que eu vejo como principal objetivo da [associação] é o desenvolvimento rural. Portanto, há algum tipo de formação que não vai muito no sentido do desenvolvimento rural, mas isso também tem a ver com o facto de as instituições terem que sobreviver e têm que ter um leque abrangente de atividades paralelas para poderem ir mexendo com o meio $[E(T) 4]$.

Nesta ordem de ideias, a educação e a formação eram vistas como instrumentos de gestão social do (pouco) emprego existente e do (crescente) desemprego, mesmo que, ao longo da sua história, estes domínios tivessem maior peso na intervenção da associação. Neste sentido, parecia existir um efeito induzido (Guimarães, Silva, \& Sancho, 2006), uma propensão sugerida pelo Estado (Lima, 2012) para a adesão a finalidades relacionadas com a educação de adultos estabelecidas aos níveis nacional ou supranacional que tinham no controlo e na regulação social aspetos essenciais. De facto, eram a educação de base (de segunda oportunidade) e a formação profissional (com vista à inserção e manutenção dos sujeito no mercado de trabalho, à promoção do crescimento económico e ao aumento da produtividade) que dominavam as ações implementadas (Guimarães, 2011).

Este efeito induzido pelo Estado tinha como resultado uma adaptação estratégica da associação a objetivos, valores e formas de trabalho que podiam não ser imediatamente articuláveis com as preocupações que levaram à sua criação, nomeadamente aquelas relacionadas com o desenvolvimento rural integrado, bem como com a cidadania democrática, a participação e transformação social. De resto, esta desarticulação era evidente sobretudo no caso das ações de formação profissional, em muitos 
casos definidas pelos serviços estatais responsáveis, como o Instituto de Emprego e Formação Profissional, mas frequentemente desadequadas face aos problemas e necessidades sentidos localmente. Apesar desta situação, esses eram os valores, os objetivos e as formas de trabalho assumidos e raramente questionados. Esta circunstância atribuía um elevado grau de profissionalização a esta entidade, favorecendo o estatuto de entidade bem sucedida: esta associação apresentava-se muito dinâmica na implementação de ações, mesmo que mais ou menos ligadas ao desenvolvimento rural integrado (Guimarães, 2011), e, em decorrência, via aumentado o reconhecimento social concedido pelas comunidades locais. Como foi dito por um dos entrevistados:

A associação tem feito um trabalho bom, bem feito, bastante bem, tem coisas muito boas. Tem marcado a sua área de atuação, está bem marcada na região, tem espaço para trabalhar e é necessária à região. (...) Vejo também que os associados da [associação], aqueles mais importantes, também reconhecem esse papel e é importante em termos de futuro. $E$ acho que isso é a base de sustentação da [associação] (...) [E(T)2].

No caso da política pública de educação e formação de adultos, a adaptação a objetivos e procedimentos dos programas da UE e do Estado português era uma condição inerente à articulação entre a lógica de serviço público e a lógica de programa. Consequentemente, esta adaptação escondia um outro problema de maior amplitude. Este relacionava-se com a dificuldade que a associação parecia manifestar em reinterpretar e recontextualizar as orientações e as normas associadas a estes programas e, em particular, em possuir um projeto educativo que contemplasse outras modalidades e iniciativas de educação de adultos de características mais críticas e emancipatórias. Estas razões levavam a que a sua intervenção local assentasse num esforço de devolução estatal (Lima, 2012) de iniciativas que apostavam na promoção da educação de base e da formação profissional de caráter inicial.

Em simultâneo, verificava-se o abandono da possibilidade de uma intervenção alternativa, mais próxima e significativa das comunidades locais e dos adultos, tal como de desenvolvimento de iniciativas de educação crítica, fomentadoras de participação ativa transformadora e de maior consciência social. Registava-se por isso pouca diversidade e heterogeneidade de ações de educação de adultos. Na verdade, a associação encontrava-se refém das 
políticas públicas. Esta era também uma circunstância que deixava a educação de adultos mais pobre, dado que não eram pensadas oportunidades inovadoras de ação educativa local. No fundo, este era um quadro no qual se reforçavam a subordinação do terceiro setor a agendas estatais, remetendo-o para um papel de auxiliador e favorecedor da gestão social de problemas como o desemprego num Estado social em retração. Devido ao peso desta subordinação, assistia-se a uma dramática diminuição de possibilidades de mudança social através de dispositivos de educação problematizadora e de criação de modos de produzir e viver inovadores (Guimarães, 2011).

\section{O papel dos agentes da educação e formação de adultos na sobrevivência da associação}

Ao contrário de muitas outras entidades sem fins lucrativos que revelavam dificuldades no acesso a oportunidades de financiamento (Guimarães, Silva, \& Sancho, 2006; Rothes, 2009), desde a sua criação, esta associação desenvolveu saberes e capacidades que the garantiram o sucesso das candidaturas que efetuava e dos projetos nos quais se envolvia. Este capital de candidatura (Rothes, 2009) estava enraizado em novas formas de governação implementadas recentemente. De caráter isomórfico, estas formas incluíam procedimentos de candidatura a diversas iniciativas nacionais e supranacionais, tarefas de monitorização e acompanhamento do trabalho levado a cabo, assim como atividades ligadas à auditoria, à prestação de contas e à avaliação do impacto local das ações desenvolvidas medido a partir de inúmeros indicadores previamente estabelecidos (Guimarães, 2011). Estas eram tarefas que se afastavam de possibilidades de autogoverno, de participação ativa em processos políticos, de oportunidades de democratização da democracia formal (Lima, 2012).

Por estas razões, esta organização oscilava entre uma entidade que integrava dimensões típicas de uma associação de tipo popular, cultural e recreativo, adotando práticas de mobilização dos associados, dirigentes, etc., de liderança participada e militância, e outras dimensões associáveis a uma instituição mais estruturada, formalizada, mais próximas de uma empresa de formação. Quando interrogados sobre o ethos da associação (enquanto 'associação popular' ou 'empresa de formação'), diversos inquiridos 
afirmaram que ela se aproximava de uma empresa, devido aos objetivos prosseguidos, ao grau de formalização e centralização do poder, ao planeamento, à capacidade de intervenção técnica, aos encargos financeiros, aos vínculos laborais, à competitividade inerente à participação em concursos de projetos. Simultaneamente, alguns discursos ainda apontavam para certos ideários políticos de emancipação social, de ativismo e mobilização voluntária. Denotando o estatuto híbrido da organização em causa, um dos inquiridos (dirigente) defendia a existência de "técnicos-militantes, que não podiam assumir-se como funcionários públicos, mas que deveriam possuir um forte espírito de missão" [E(D)1]. A associação era igualmente representada por um outro entrevistado (também dirigente) como "uma empresa, na qual os técnicos deveriam ter amor à camisola" [E(D)2]. Pelo seu lado, os técnicos possuíam opiniões que situavam a associação bem mais próxima de uma entidade com fins lucrativos. Assim, relativamente ao funcionamento e à intervenção destes agentes, houve quem dissesse que esta entidade "nada tinha a ver com uma associação" $[E(T) 3]$ e que "não podia estar do lado do voluntarismo. Exigia competências técnicas de nível superior" $[E(T) 2]$ (Lima, Guimarães, \& Oliveira, 2007, pp. 33-34).

Não sendo possível afirmar que a associação estudada era uma entidade orientada para o mercado, possuidora de objetivos que se dirigiam para a resolução de problemas apresentados pelos consumidores, as novas formas de regulação impostas induziam a existência de parcerias subordinadas a agendas públicas de gestão de profundas transformações (económicas e sociais) ocorridas ao nível local. De um lado, estas formas de regulação eram justificadas pela necessidade de controlar e avaliar a qualidade do trabalho de entidades não-estatais, garantindo eficácia e eficiência relativamente aos objetivos estabelecidos. Estes modos de intervir aproximavam o funcionamento desta associação do de outras de características marcadamente empresariais (Lima, 2012) e traduziam um maior grau de profissionalização aos agentes que nela trabalhavam.

Esta aproximação a valores de gestão empresarial, no qual se aprofundava a orientação autocentrada da entidade (Monteiro, 2004), envolvia diversos problemas. Um primeiro relacionava-se com a adesão a normas inerentes aos programas de financiamento. De facto, se estas garantiam a sustentabilidade da associação, surgiam como um dos mais 
significativos entraves à sua existência. A necessidade de conhecer as estratégias para tornar os projetos candidatados em ações aprovadas encerrava um dilema: ou a associação se adaptava a novas formas de regulação definidas externamente e procurava operar através do recurso a formas de ação tecnicizadas e burocratizadas (que podiam não ser totalmente consentâneas com as finalidades com que foi estabelecida, e até com os objetivos mais significativos para as comunidades locais), ou reinterpretava modos de trabalho que respeitavam a autonomia individual e coletiva, o autogoverno, a democracia participativa (e não conseguia oferecer muitas das atividades que promovia, manter os profissionais, etc.). Em boa verdade, apesar da existência de associados e das respetivas quotas de participação, era nos financiamentos externos que a associação obtinha os recursos que garantiam a sua existência. Consequentemente, eram multiplicadas as responsabilidades, acrescentando objetivos e estratégias de intervenção que nem sempre eram associáveis às suas finalidades originais. Como referiu um dos entrevistados ao comparar o trabalho levado a cabo em meados da década de 1990 com aquele desenvolvido na atualidade: "Quando o LEADER apareceu e eu comecei a trabalhar nisto, éramos muito mais aguerridos. O desenvolvimento local era mais aguerrido" $[E(T) 2]$. Ou ainda, como foi acrescentado,

Toda a primeira fase do Programa LEADER foi uma maravilha. Tínhamos muito trabalho no terreno. Trabalhávamos com as pessoas. Tínhamos tempo para detetar projetos, pessoas que queriam investir. Tínhamos mais tempo para a sensibilização, para a área do que chamávamos a extensão rural, de mobilizar as pessoas. (...) Nos primeiros tempos em que eu comecei a trabalhar aí num centro, se calhar foi o trabalho que mais gozo me deu em termos de desenvolvimento rural; foi mesmo um trabalho que começou... ir ali com um carrinho, um caderninho: "O que quer? O que precisa?"... foi mesmo um trabalho que começou de baixo para cima. É aquilo que eu hoje não consigo fazer" $[E(T) 2]$.

Um segundo problema (decorrente deste primeiro) ligava-se ao impacto destas formas de regulação no quotidiano da associação. As estratégias profissionais que se orientavam para a adaptação e acomodação desta organização a orientações definidas ao nível mega (nomeadamente pela União Europeia) e ao nível macro (com origem no Estado português) surgiam como uma exigência, aprisionando os agentes a inúmeras tarefas técnicas e obrigando à reserva de muito tempo para a conservação das 
parcerias com o Estado. Estabelecia-se assim um ciclo vicioso de cultura de contrato (Field, 2006) que alimentava a devolução estatal (Lima, 2012) e impunha uma vigilância constante. Como foi referido, "Nós estamos sempre em contacto com os vários programas e sempre que nos surja uma candidatura, uma possibilidade, nós fazemos... estamos atentos. Esta candidatura tem interesse, vamos apresentá-la" $[E(T) 1]$.

Diariamente, o trabalho realizado por esta associação envolvia o desenvolvimento de um conjunto muito significativo de tarefas de caráter administrativo, de gestão, de execução, de acompanhamento e de avaliação, designadamente no caso dos projetos de reabilitação e conservação de património edificado e natural, bem como daqueles ligados à educação e formação de adultos. Este trabalho era essencial para esta entidade, pois reforçava o grau de implantação nas comunidades locais, enquanto assegurava a sua sobrevivência institucional (Lima \& Afonso, 2006). Esta era uma capacidade estratégica que determinava uma plasticidade de intervenção alargada, uma capacidade de adaptação induzida e contextualizada relativamente aos programas e aos procedimentos externamente impostos, ou, como alega Montaño (2002, pp. 208-215), uma elevada capacidade de obtenção de recursos, que escamoteava os fundamentos da missão da organização.

O esforço destes agentes tinha na sobrevivência institucional desta entidade um motivo suficientemente forte para que fossem aceites as imposições que eram efetuadas quer pelo Estado português, quer pela UE para a educação de adultos. E, se esta sobrevivência dependia de uma transferência para esta entidade de níveis de gestão e de administração da provisão educativa que anteriormente pertenciam ao Estado, esta circunstância não era criticada. Nesta perspetiva, nunca era questionado o estatuto de organização de mediação que a associação acabava por merecer no âmbito da concretização de objetivos estatais de gestão social de problemas como o emprego e o desemprego, a formação e a adaptação de recursos humanos. Tão pouco era interrogado o facto de esta entidade integrar modos de funcionamento que a aproximavam das empresas (Lima, 2012), num quadro de competição com outras entidades congéneres e da procura da excelência das iniciativas educativas e formativas implementadas (Laville et al., 1997), no que era designado de boas práticas. Muito menos era 
problematizada a política pública de educação de adultos quando integrava ofertas que tinham como finalidade o crescimento económico, o aumento da produtividade e da competitividade nacionais, quando regiões como aquela na qual a associação se inseria não viam contemplados projetos de âmbito local favorecedores de transformação social e participação democrática.

\section{Reflexões finais}

A sociedade civil apresenta-se como uma entidade heterogénea, incluindo organizações muito diferentes entre si que revelam formas de intervenção também muito variadas. De entre essas instituições, há associações da sociedade civil que têm ocupado um lugar de aprendizagem e de promoção da mudança social (Melo \& Benavente, 1978), locus privilegiado da luta de classes (Montaño, 2002), ao favorecer a eclosão de outros saberes e conhecimentos relevantes para a participação em lutas diversas e em movimentos de emancipação social, em muitas circunstâncias desenvolvendo estratégias contra o Estado. De resto, diversos autores têm valorizado os contributos das associações do terceiro setor para a dinamização da sociedade civil e da educação de adultos. Estas entidades podem assumir um papel de contrapoder (Lima \& Afonso, 2006). No seu melhor, estas organizações podem surgir como agentes de transformação social, com uma intervenção importante aos níveis local, nacional e global. De facto, podem dinamizar iniciativas que permitem aos indivíduos e às comunidades nas quais se inserem enfrentar, resistir e mudar as relações de poder que resultam do desenvolvimento da economia capitalista (Lima, Guimarães, \& Oliveira, 2007, p. 41). Estas organizações têm sido igualmente consideradas relevantes para a sobrevivência da esfera pública, dado que estão mais sensíveis aos problemas das populações e são mais conhecedoras das formas de os resolver. À partida, estas entidades caracterizam-se por gozar de um elevado grau de autonomia relativamente ao Estado e, neste sentido, estariam melhor preparadas para a provisão de serviços sociais relevantes para as comunidades locais (Turner, 2001), designadamente de ações de educação crítica, transformadora e emancipatória.

Todavia, o caso em discussão neste texto procurou ilustrar a hibridez de muitas das organizações da sociedade civil. De facto, os dados discutidos 
neste texto revelam tendências que apontam para fortes tensões e ambivalências na intervenção de certas organizações da sociedade civil. De um lado, no quadro da retração do Estado, assiste-se a novas formas de expansão do Estado, através do aumento da sua atividade interventora e reguladora. Em domínios como a educação de adultos, diferentes organizações formalmente não estatais assumem orientações e formas de ação até recentemente associadas ao Estado, nomeadamente no âmbito da educação de base. Num esforço de devolução estatal, a associação estudada passou a exercer poderes tradicionalmente públicos, designadamente no contributo para a certificação escolar, transformando-se, através da ação do Estado, numa entidade para-estatal ou numa extensão de serviços estatais. Nestas circunstâncias, como afirma Santos (1990), a distinção entre Estado e sociedade civil torna-se problemática, "tal como se torna cada vez mais difícil determinar onde acaba o Estado e a sociedade civil começa" (p. 24): o Estado retrai-se de áreas de intervenção mais tradicionais (por exemplo, do Estadoprovidência) e expande-se sob a forma de sociedade civil.

Segundo esta perspetiva, o projeto de investigação base deste artigo procurou ilustrar como uma organização do terceiro setor, uma associação de desenvolvimento local que possuía uma forte ligação às comunidades locais nas quais intervinha, adotou estratégias de mediação, no âmbito de parcerias estabelecidas com o Estado e com a União Europeia, passando a partilhar igualmente com as empresas algumas características. Esta circunstância levantou diversas questões sobre a independência e a sua capacidade de desenvolver projetos educativos de caráter emancipatório e de resolução de problemas sentidos pelas populações locais. No fundo, o que o caso analisado procurou mostrar foi que, no quadro da retração/expansão do Estado e do fomento às parcerias, o terceiro setor apresentou-se com um espaço no qual era possível encontrar processos educativos marcadamente instrumentais, dinamizados através de políticas orientadas para a gestão social do emprego e do desemprego, bem como para o crescimento económico, para o aumento da produtividade e para a competitividade. Neste sentido, este artigo destacou as estratégias adaptativas e gerencialistas às quais uma entidade do terceiro setor aderiu. Estas estratégias levaram a que esta organização desenvolvesse sobretudo processos de controlo e regulação social (Guimarães, 2011; Lima, 2012). 
Este artigo procurou debruçar-se sobre as profundas transformações ocorridas no terceiro setor com intervenção na educação de adultos, acompanhadas pela erosão do movimento associativo. Nestas transformações, pareceu registar-se uma crescente importância atribuída à captação de recursos financeiros e à profissionalização das entidades, bem como, simultaneamente, uma progressiva dependência face ao Estado e aos poderes públicos, acompanhada de uma adaptação a modos de regulação mais característicos das empresas (Guimarães, 2011). Em boa verdade, nos tempos mais recentes, o terceiro setor parece ter contrariado os motivos que levaram ao seu surgimento ainda no século XIX. Emergiu como um parceiro na implementação de políticas sociais, como 'extensão de serviços públicos', regendo-se por critérios de eficácia e eficiência, mas raramente assumindo o seu papel de coprodutor de orientações políticas e programas de ação de autogestão e participação social. Por isso, no quadro do condicionamento das entidades do terceiro sector a orientações de devolução estatal e da construção de um mercado de aprendizagem que implica uma crise de valores associativos de resistência e de oposição ao Estado e de modos de funcionamento mais democráticos, são cada vez mais exíguos os espaços que favorecem a existência de associações promotoras de educação crítica e transformadora.

\section{Nota}

1 Esta associação foi criada a 4 de setembro de 1991 e estava sedeada em Vila Verde, num edifício que lhe pertencia, uma casa senhorial rural que dispunha de duas edificações. Numa primeira, de três andares, localizavam-se os serviços administrativos e de gestão; numa segunda, de dois andares, podiam encontrar-se as diferentes salas nas quais os Cursos EFA decorriam. Entre estas edificações, existia um jardim, com um espigueiro. Esta casa, construída nos finais do século XIX, foi reconstruída pela associação ao longo da década de 1990, a partir de um projeto arquitetónico realizado por um dos técnicos que a integrava. Esta reconstrução foi efetuada com preocupações de modernizar e tornar mais eficientes os espaços interiores do edifício reservados às diferentes tarefas realizadas. Globalmente, esta organização encontrava-se bem equipada, dispondo de equipamento diverso e de várias viaturas que eram utilizadas pelos seus técnicos, aquando das visitas aos projetos de reconstrução e de reabilitação que eram empreendidos. Esta entidade integrava mais de uma dezena de técnicos. Destes, a técnica administrativa da associação, que prestava apoio a todos os técnicos, era a única que possuía unicamente o $12^{\circ}$ ano como habilitação académica; todos os 
outros técnicos detinham licenciaturas em áreas específicas, ligadas mais ou menos diretamente ao desenvolvimento rural e à preservação do património (como, por exemplo, a Engenharia Agrícola e a Arquitetura, e as Ciências Sociais, como, por exemplo, a Educação, as Relações Públicas e as Relações Internacionais, de acordo com os documentos internos de caracterização dos recursos humanos consultados) (cf. Guimarães, 2011).

\section{Referências}

Bardin, L. (1977). Análise de conteúdo. Lisboa: Edições 70.

Bogdan, R. C., \& Biklen, S. K. (1982). Qualitative research for education: An introduction to theory and methods. Boston: Allyn e Bacon, Inc.

Canário, R. (2007). Aprender sem ser ensinado. A importância estratégica da educação não formal. In Conselho Nacional de Educação, A educação em Portugal (19862006). Alguns contributos de investigação (pp. 207-267). Lisboa: Conselho Nacional de Educação.

Canário, R. (2009). Associativismo e educação popular. In R. Canário \& S. Rummert (Orgs.), Mundos do trabalho e aprendizagem (pp. 133-154). Lisboa: Educa.

Comissão de Reforma do Sistema Educativo (1988). Documentos preparatórios III/Comissão de Reforma do Sistema Educativo. Lisboa: GEP/Ministério da Educação.

Field, J. (2006). Lifelong learning and the educational order. Stoke on Trent: Trentham Books.

Fragoso, A., \& Guimarães, P. (2010). Is there still a place for social emancipation in public policies? Envisioning the future of adult education in Portugal. RELA European Journal for Research on the Education and Learning of Adults, 1(1-2), 17-32.

Griffin, C. (1999a). Lifelong learning and social democracy. International Journal of Lifelong Education, 18(5), 329-324.

Griffin, C. (1999b). Lifelong learning and welfare reform. International Journal of Lifelong Education, 18(6), 431-452.

Grupo de Missão para o Desenvolvimento da Educação e Formação de Adultos (2001). S@ber+. Programa para o desenvolvimento e expansão da educação de adultos (1999-2006). Lisboa: Agência Nacional de Educação e Formação de Adultos.

Guimarães, P. (2011). Políticas de educação de adultos em Portugal (1999-2006). A emergência da educação e formação para a competitividade. Braga: CIED Universidade do Minho.

Guimarães, P., Silva, O. S., \& Sancho, A. V. (2006). Educação e formação de adultos nas associações: Iniciativas popularmente promovidas ou formalmente organizadas? In L. C. Lima (Org.), Educação não escolar de adultos. Iniciativas de educação e formação de adultos em contextos associativos (pp. 25-70). Braga: UEA - Universidade do Minho. 
Laville, J.-L., Evers, A., Poujol, G., \& Vaillancourt, Y. (1997). Conclusion: Association et société. In J.-L. Laville \& R. Sainsaulieu (Dirs.), Sociologie de l'association. Des organisations à l'épreuve du changement social (pp. 321-376). Paris: Desclée de Brouwer.

Lessard-Hébert, M., Goyette, G., \& Boutin, G. (2005). Investigação qualitativa. Fundamentos e práticas. Lisboa: Instituto Piaget.

Lima, L. C. (1995). The democratization of democracy. A south European view on European democracy and citizenship education. In J. Timmer \& R. Veldhuis (Edts.), Political education. Towards a European democracy. Report of a European conference (pp. 38-44). Maastricht: Instituut voor Publiek en Politiek/Bundeszentrale für politische Bildung.

Lima, L. C. (2012). Aprender para ganhar, conhecer para competir. Sobre a subordinação da educação na "Sociedade da Aprendizagem". São Paulo: Cortez.

Lima, L. C., \& Afonso, A. J. (2006). Políticas públicas, novos contextos e actores em educação de adultos. In L. C. Lima (Org.), Educação não escolar de adultos. Iniciativas em contextos associativos (pp. 205-229). Braga: UEA - Universidade do Minho.

Lima, L. C., Guimarães, P., \& Oliveira, R. (2007). Estudo I - Organização associativa e produção local de políticas de educação de adultos. In R. V. Castro (Org.), Os Cursos EFA numa associação local. Contexto organizacional, orientações e práticas de educação de adultos (pp. 15-45). Vila Verde: ATAHCA/UEA Universidade do Minho.

Melo, A. (2007). O papel das organizações do $3^{\circ}$ sector na aprendizagem ao longo da vida. Cadernos Sociedade e Trabalho, $n^{\circ}$. 10 (Aprendizagem ao Longo da Vida), 7-24.

Melo, A., \& Benavente, A. (1978). Educação popular em Portugal (1974-1976). Lisboa: Livros Horizonte.

Melo, A., Queirós, A. M., Silva, A. S., Rothes, L., \& Ribeiro, M. (1998). Uma aposta educativa na participação de todos. Documento de estratégia para o desenvolvimento da educação de adultos. Lisboa: Ministério da Educação.

Montaño, C. (2002). Terceiro setor e questão social. Crítica ao padrão emergente de intervenção social. São Paulo: Cortez Editora.

Monteiro, A. (2004). Associativismo e novos laços sociais. Coimbra: Quarteto.

Norbeck, J. (1983). Associações populares para o desenvolvimento. Lisboa: DirecçãoGeral de Educação de Adultos.

Rothes, L. (2009). Recomposição induzida do campo da educação básica de adultos. Lógicas de apropriação local num contexto político-institucional redefinido. Lisboa: Fundação Calouste Gulbenkian/Fundação para a Ciência e Tecnologia.

Ruas, H. B. (1978). Educação de adultos em Portugal, no passado e no presente. In M. J. Gusmão \& A. J. G. Marques (Coords.). Educação de adultos (pp. 269-300). Braga: Universidade do Minho.

Santos, B. S. (1990). O Estado e o Direito na transição pós-moderna: Para um novo senso comum sobre o poder e o Direito. Revista Crítica de Ciências Sociais, 30, 13-41. 
58 Paula Guimarães

Santos, B. S. (1994). Pela mão de Alice. O social e o político na pós-modernidade. Porto: Afrontamento.

Santos, B. S. (1998). A reinvenção solidária e participativa do Estado. Intervenção no Seminário Internacional "Sociedade e Reforma do Estado", São Paulo (Brasil), 26 a 28 de março de 1998. Disponível em http://ns1.dhnet.org.br/ direitos/.../boaventura/boaventura_solidaria.pdf

Silva, A. S. (1990). Educação de adultos. Educação para o desenvolvimento. Rio Tinto: Edições ASA.

Turner, B. S. (2001). The erosion of citizenship. British Journal of Sociology, 52(2), 189209.

Yin, R. K. (1994). Case study research. Design and methods. London: Sage Publications, Inc. 


\title{
THE THIRD SECTOR IN ADULT EDUCATION: TENSIONS AND AMBIVALENCES
}

\begin{abstract}
The third sector has an important role in the promotion of adult education, training and learning as well as in social change in local communities that have been progressively excluded from hegemonic processes of economic development. However, many non-governmental organisations have adopted mediation strategies between the State and local communities in the frame of partnerships and have shared characteristics with enterprises. This fact raises doubts concerning these organisations' autonomy and on their capacity to develop educational and emancipatory projects. This article aims at discussing transformations occurred in the third sector which is involved in adult education. This analysis relates these changes with the erosion of the associations' dynamics. Data discussed was collected within a research project focused on a case study of the public policy of adult education after 1999 and a local development association that promoted specific provision of adult education forms.
\end{abstract}

Keywords

Adult education; Third sector; Public policy

\section{LES ASSOCIATIONS ET L'ÉDUCATION DES ADULTES: TENSIONS ET AMBIVALENCES}

\author{
Résumé \\ Le troisième secteur a toujours occupé une place importante dans la \\ promotion de l'éducation, la formation et l'apprentissage des adultes et dans \\ le changement social des communautés locales qui sont de plus en plus \\ exclus des procès hégémoniques de développement. Mais beaucoup \\ d'organisations non gouvernementales ont adoptées des stratégies de \\ médiation entre l'État et les communautés locales en établissent des
}


60) Paula Guimarães

partenariats. Ces organisations présentent aujourd'hui certaines caractéristiques communes aux entreprises. Ce fait a mis en cause leur autonomie et questionne la capacité du troisième secteur de développer des projets éducatifs et d'émancipation. Cet article discute les transformations du troisième secteur avec intervention dans l'éducation des adultes. Cette analyse est faite a partir de données récoltés dans un projet de recherche qui a privilégié une étude de cas d'une politique publique d'éducation d'adultes implémentée après 1999 par une association de développement locale.

Mots-clé

Éducation des adultes; Troisième secteur; Politique publique

Recebido em julho, 2012

Aceite para publicação em julho, 2013

i Instituto de Educação, Universidade de Lisboa, Portugal

Toda a correspondência relativa a este artigo deve ser enviada para: Paula Guimarães, Instituto de Educação da Universidade de Lisboa, Alameda da Universidade, 1349-013 Lisboa, Portugal. Email: pguimaraes@ie.ul.pt 